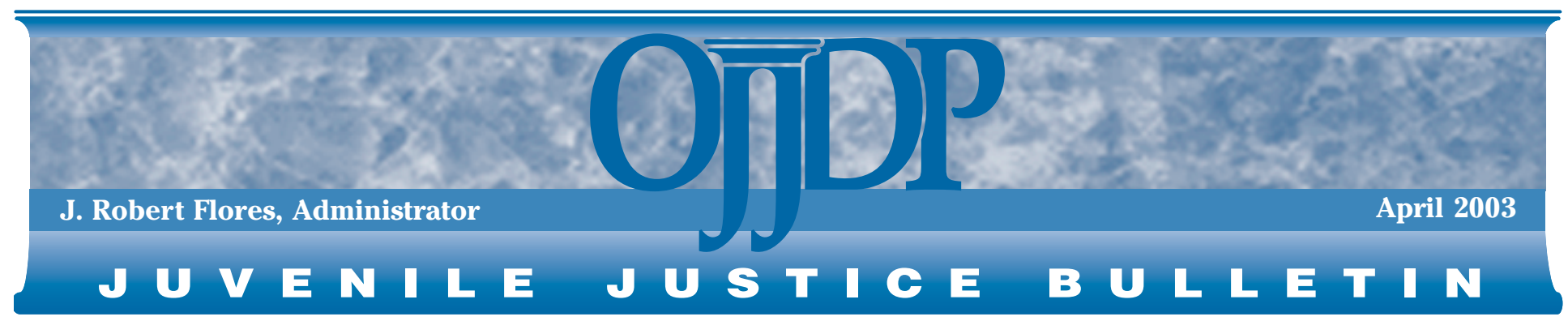

\section{Race as a Factor in Juvenile Arrests}

\section{Carl E. Pope and Howard N. Snyder}

Race-related issues are a major concern in the criminal and juvenile justice systems. This Bulletin focuses on a specific aspect of that concern within the juvenile justice system: the effects of race on police decisions to take juvenile offenders into custody.

The Bulletin begins with background information, including a brief review of the research literature to date. It then analyzes recent data from the Federal Bureau of Investigation's (FBI's) National IncidentBased Reporting System (NIBRS) for evidence of racial bias in juvenile arrests for violent crimes. Overall, the analysis reveals no direct evidence that such bias exists.

\section{Background}

A wide array of literature has been published over the past 50 years dealing with the degree to which race affects juvenile justice decisionmaking. Research findings tend to be contradictory, in that some studies find evidence of racial bias and others do not. This inconsistency is not surprising because different studies have used different designs, timeframes, and jurisdictions.

For example, one study (Pope et al., 1996) found that race, per se, did not affect outcomes of juvenile justice processing in four of the five Wisconsin counties studied. In these counties, no race-related differences in decisionmaking were apparent after the initial intake decision-youth were treated similarly at all decision stages, regardless of race. In Milwaukee, the largest metropolitan county in the state, African American youth were overrepresented (relative to their share of the total juvenile population) at all stages of processing; however, race (i.e., being African American) did not account for these differences. Factors that predicted whether a youth would be held in secure confinement included severity of the offense, prior secure confinement, and whether a youth was on state probation; race was not a significant factor. However, a Michigan study (Wordes, Bynum, and Corley, 1994) did find that minority youth were more likely than white youth to be detained in a secure facility. As the researchers note, "Across all analysis, youth who were African American or Latino were consistently more likely to be placed in secure detention. This was observed in the detention practices of both the police and the courts" (p. 162).

These two studies illustrate the differences in research findings on the effects of race in juvenile justice decisionmaking. The Wisconsin study found no significant effects at all, but the Michigan study

\section{A Message From OJJDP}

The depiction of justice as a blind-folded figure holding a set of scales illustrates our belief that fair treatment-regardless of race-is integral to the very concept of justice in the United States. What role, if any, does racial bias play in our juvenile justice system?

Although a broad array of research over the past half century has explored the degree to which race impacts the juvenile justice system, the results are mixed. Some studies have found evidence of racial bias, while others have found that race is not a significant factor.

Such diverse findings have contributed to correspondingly distinct perspectives on the present state of juvenile justice. Some observers claim that the juvenile justice system is biased against minority offenders, while others argue that in general the system treats all offenders in an equitable manner.

The authors of this Bulletin focus on a somewhat neglected area of research, i.e., the role that race plays in police decisionmaking. Using statistics from the FBl's National Incident-Based Reporting System, they compare arrest probabilities of white and nonwhite juveniles for violent crimes. Their investigation finds no direct evidence that an offender's race affects police decisions to take juveniles into custody in such incidents. Thus, it sheds light on one critical question about race and justice and reminds us that others remain to be answered. 
did find significant effects with regard to secure detention. Again, this is not surprising given the fact that juvenile justice is "fragmented" (i.e., many different systems rather than a single, uniform system) and what occurs in one jurisdiction may well not be the same as what occurs in another.

Despite the lack of consensus in findings, these two studies and other research (Pope, 1994) underscore the fact that the issue of race is central to the administration of justice in this country. Two fundamentally different perspectives on the issue have emerged.

Some observers argue that the justice system is biased against minority offenders (the race-related selection bias perspective). With regard to juvenile justice, these observers often point to the fact that African American youth are more likely to be arrested than other youth. In 1997, for example, 44 percent of juvenile arrests for violent crimes involved African American youth, although African Americans represented only 15 percent of the national juvenile population at the time (Snyder, 1998). In 1997, minorities accounted for 67 percent of juveniles committed to public facilities nationwidenearly twice their representation in the juvenile population (Snyder and Sickmund, 1999). In addition, national data show that minority juvenile offenders are more likely than white non-Hispanic offenders to be placed in public (rather than private) custodial facilities (Snyder and Sickmund, 1999).

Other observers argue that, although there are some exceptions, overall the justice system is fair and treats offenders similarly regardless of their race or ethnicity (Wilbanks, 1987). These observers usually note that, unfortunately, minority youth are committing most of the crime and are thus "doing most of the time." They point to crime-generating conditions such as underemployment, poverty, lack of opportunity, family dysfunction, and other structural factors (see, for example, McCord, 1997; Pope, 1999). Snyder and Sickmund (1999) note that minority youth may be overrepresented within the juvenile justice system because of behavioral and legal factors (e.g., more extensive offense histories)what can be called the behavioral-legal perspective.

Thus, one perspective focuses on the operation of juvenile justice systems while the other focuses on the behavior of individual juveniles who commit crime. Which perspective is correct? This is a difficult question to answer, and the truth may never be known with absolute certainty. There is research evidence to support both perspectives (see Lovell and Pope, 1991), and the answer may well be a combination of the two, depending on where and how the research is conducted.

Traditionally, research on race and juvenile justice has focused on four major decision points in the juvenile justice systemintake, detention, adjudication, and disposition. It is perhaps not surprising that few research studies have focused on police encounters with juveniles. These encounters are rather difficult to measure, as they tend to be low-visibility events that take place spontaneously on the streets. However, studies that have examined such encounters have generally found that police decisionmaking does contribute to minority overrepresentation in the juvenile justice system. This is simply an observation that, within their scope of responsibility, police decide when to arrest and when not to arrest, and to the extent that this decisionmaking process results in the arrest of African American youth at a higher rate than white youth, it contributes to overrepresentation. Without more information, though, it is impossible to say whether that overrepresentation is the result of police bias or differential behavior.

Thus, while some researchers have suggested racial bias as a possible explanation for these disparities (Conley, 1994, Pope et al., 1996; Sealock and Simpson, 1998; Bynum, Wordes, and Corley, 1993; Hartstone and Richetelli, 1995; Bridges et al., 1993; Austin, Dimas, and Steinhardt, 1991), past studies have paid little attention to the underlying objective factors that contribute to the street-level decisions in question, leaving a gap in the knowledge about racial bias in juvenile arrests. The next section analyzes recent FBI data with a view toward filling that gap.

\section{Analysis of Statistical Evidence}

\section{The Data}

Traditionally, the aggregate reported crime and arrest statistics of the FBI's Uniform Crime Reporting Program could not be used to assess relative probabilities of arrest (e.g., whether minority juveniles are more likely than nonminorities to be arrested for similar offenses). The FBI's aggregate data provided demographic information on arrestees but not on all reported offenders; therefore, the data could not be used to determine what proportion of all minority offenders known to law enforcement were eventually arrested.

In the late 1980s, the FBI proposed, and supported the development of, a new standard for reporting crime and arrest statistics, the National Incident-Based Reporting System. Through NIBRS, the FBI asks law enforcement agencies to record a substantial amount of information on each reported crime and each arrest. For example, when an aggravated assault is reported to a law enforcement agency, the agency is asked for the following information:

- Age, sex, and race of the victim(s).

$\checkmark$ Offense(s) involved.

$\checkmark$ Date and time of the incident.

$\checkmark$ Type of place where the incident occurred.

- Each victim's level of injury.

-Weapon(s) used, if any.

- Victim's perception of the demographics of the offender(s), including age, sex, and race.

$\checkmark$ Victim-offender relationship(s).

- Demographics of arrestee(s), determined when an arrest occurs.

$\checkmark$ Date of each arrest.

Researchers can examine NIBRS data on the types of incidents likely to involve victim-offender interaction, determine the victim's perception of the offender in each incident, study which incidents resulted in arrests, and then compare, for example, the arrest probabilities of white and nonwhite juvenile offenders for similar crimes. More generally, researchers can determine which crime incident characteristics increase the likelihood that an arrest will be made and whether, for juvenile offenders, race is one of these characteristics.

The data for this study come from the 1997 and 1998 NIBRS master files, which were compiled and distributed by the FBI. These files contain information on all incidents that occurred in certified jurisdictions ${ }^{1}$ during each of these calendar

\footnotetext{
1 A law enforcement agency's data are certified once they have met the FBI's strict reporting standards. These standards require that all reported data fall within the valid coding values for each data element.
} 
years and all arrests resulting from these incidents that occurred as of December 31 of the following year. The data were available from law enforcement agencies in 17 states (Colorado, Connecticut, Idaho, Iowa, Kentucky, Massachusetts, Michigan, Nebraska, North Dakota, Ohio, South Carolina, Tennessee, Texas, Utah, Vermont, Virginia, and West Virginia). Incidents selected for this study were those in which the most serious offense was murder, a violent sex offense, robbery, aggravated assault, simple assault, or intimidation-all incidents involving victim-offender contact. For each offender in each incident, a record was prepared containing the victim's perception of the offender's demographics and the details of the incident.

Although it cannot be claimed that the sample of law enforcement agencies represented by the NIBRS data is nationally representative, the data did yield a large sample of 141,786 juvenile offenders (i.e., offenders who were identified by their victims as younger than age 18). From this initial sample, 27 percent were excluded from the analysis because at least one of the key characteristics listed in the previous column was missing. A comparison of records that were excluded from the analysis with those that were included in it found no substantial differences in victim, offender, place, injury, or weapon attributes. The final base for the analysis, after incomplete records were excluded, contained information for 102,905 juvenile offenders.

\section{Analysis and Results}

The NIBRS data provide a profile of the characteristics of violent crimes that were reported to law enforcement agencies and that victims attributed to juvenile offenders. For most offenders (59.8 percent), simple assault was the most serious charge in the recorded incident. Far less common were aggravated assault (18.9 percent), intimidation (9.2 percent), violent sex offenses (7.7 percent), robbery (4.0 percent), kidnapping/abduction (0.4 percent), and murder/nonnegligent manslaughter (0.1 percent).

As shown in table 1, most offenders (81.8 percent) committed their crime against a lone victim, and most (63.2 percent) committed their crime alone. Most (74.9 percent) committed their crime inside a structure. About one-fifth (18.2 percent)

Table 1: Incident Characteristics of Violent Crimes by Juvenile Offenders

\begin{tabular}{|c|c|c|c|}
\hline \multirow[b]{2}{*}{ Offense Characteristic } & \multicolumn{3}{|c|}{ Offenders (\%) } \\
\hline & $\begin{array}{c}\text { All } \\
(n=102,905)\end{array}$ & $\begin{array}{c}\text { White } \\
(n=71,246)\end{array}$ & $\begin{array}{l}\text { Nonwhite } \\
(n=31,659)\end{array}$ \\
\hline \multicolumn{4}{|l|}{ Was offender arrested? } \\
\hline No & 65.8 & 64.1 & 69.6 \\
\hline Yes & 34.2 & 35.9 & 30.4 \\
\hline \multicolumn{4}{|l|}{ Number of victims } \\
\hline One & 81.8 & 82.8 & 79.8 \\
\hline More than one & 18.2 & 17.2 & 20.2 \\
\hline \multicolumn{4}{|l|}{ Number of offenders } \\
\hline One & 63.2 & 67.1 & 54.4 \\
\hline More than one & 36.8 & 32.9 & 45.6 \\
\hline \multicolumn{4}{|l|}{ Location of incident } \\
\hline Outdoors & 25.1 & 21.7 & 32.8 \\
\hline Indoors & 74.9 & 78.3 & 67.2 \\
\hline \multicolumn{4}{|l|}{ Most serious weapon } \\
\hline Personal & 81.8 & 84.0 & 77.0 \\
\hline Nonpersonal & 18.2 & 16.0 & 23.0 \\
\hline \multicolumn{4}{|l|}{ Victim age } \\
\hline Juvenile & 60.7 & 62.1 & 57.6 \\
\hline Adult & 39.3 & 37.9 & 42.4 \\
\hline \multicolumn{4}{|l|}{ Victim sex } \\
\hline Female & 47.0 & 46.8 & 47.6 \\
\hline Male & 53.0 & 53.2 & 52.4 \\
\hline \multicolumn{4}{|l|}{ Victim race } \\
\hline White & 77.4 & 96.7 & 34.0 \\
\hline Nonwhite & 22.6 & 3.3 & 66.0 \\
\hline \multicolumn{4}{|l|}{ Was victim injured? } \\
\hline No & 53.8 & 53.9 & 53.6 \\
\hline Yes & 46.2 & 46.1 & 46.4 \\
\hline \multicolumn{4}{|c|}{ Was offender a family member? } \\
\hline No & 78.3 & 76.2 & 82.8 \\
\hline Yes & 21.7 & 23.8 & 17.2 \\
\hline \multicolumn{4}{|c|}{ Was offender an acquaintance? } \\
\hline No & 32.0 & 31.4 & 33.3 \\
\hline Yes & 68.0 & 68.6 & 66.7 \\
\hline \multicolumn{4}{|l|}{ Was offender a stranger? } \\
\hline No & 84.6 & 87.9 & 77.2 \\
\hline Yes & 15.4 & 12.1 & 22.8 \\
\hline \multicolumn{4}{|l|}{ Offender sex } \\
\hline Female & 26.8 & 26.5 & 27.7 \\
\hline Male & 73.2 & 73.5 & 72.3 \\
\hline \multicolumn{4}{|l|}{ Offender race } \\
\hline White & 69.2 & & \\
\hline Nonwhite & 30.8 & & \\
\hline
\end{tabular}

of offenders possessed a firearm, knife, club, or other nonpersonal weapon during the crime. Most juvenile offenders (60.7 percent) victimized other juveniles. About equal proportions of offenders victimized males (53.0 percent) and females (47.0 percent). A greater proportion of offenders victimized acquaintances ( 68.0 percent) than 
family members (21.7 percent) or strangers (15.4 percent). ${ }^{2}$ About one-half of the offenders (46.2 percent) injured their victims during the incident. In this sample, most offenders were male (73.2 percent) and most were white (69.2 percent).

Overall, for the crime incidents covered in this analysis, white juveniles were significantly more likely to be arrested than nonwhite (i.e., primarily African American) juveniles. ${ }^{3}$ Based on victims' perceptions, 69.2 percent of all juvenile offenders were white; however, 72.7 percent of all juvenile offenders arrested were white. Law enforcement agencies arrested 34.2 percent of all juvenile offenders reported to them, 35.9 percent of all white juvenile offenders reported to them, and 30.4 percent of all nonwhite juvenile offenders reported to them.

The arrest proportions for white and nonwhite juvenile offenders noted above are based on a simple cross-tabular comparison that does not take into account any differences in the characteristics of incidents involving white and nonwhite offenders. Some of the disparity in arrest proportions may be accounted for by such differences (see table 1). Compared with nonwhite juvenile offenders, white juvenile offenders were:

- Less likely to have multiple victims (17.2 percent of white offenders versus 20.2 percent of nonwhite offenders).

- More likely to act alone (67.1 percent of white offenders versus 54.4 percent of nonwhite offenders).

- More likely to commit crimes indoors (78.3 percent of white offenders versus 67.2 percent of nonwhite offenders).

- Less likely to possess a nonpersonal weapon, such as a firearm, knife, or club (16.0 percent of white offenders versus 23.0 percent of nonwhite offenders).

\footnotetext{
2 The victim-offender relationship proportions add to more than 100 percent because some offenders victimized more than one person in the incident and sometimes these multiple victims fell into different relationship categories

3 NIBRS distinguishes four racial groups: white, African American, Native American, and Asian/Pacific Islander. In this NIBRS sample, very few offenders were classified as Native American or Asian/Pacific Islander.
}

$\checkmark$ Less likely to offend against adults (37.9 percent of white offenders versus 42.4 percent of nonwhite offenders).

- Equally likely to offend against females (46.8 percent of white offenders and 47.6 percent of nonwhite offenders).

- Less likely to offend against members of another race (3.3 percent of white offenders versus 34.0 percent of nonwhite offenders).

- Equally likely to injure victims (46.1 percent of white offenders and 46.4 percent of nonwhite offenders). ${ }^{4}$

- More likely to commit crimes against family members ( 23.8 percent of white offenders versus 17.2 percent of nonwhite offenders), about equally likely to commit crimes against acquaintances (68.6 percent of white offenders and 66.7 percent of nonwhite offenders), but less likely to commit crimes against strangers (12.1 percent of white offenders versus 22.8 percent of nonwhite offenders).

Because incidents involving white offenders differed from those involving nonwhite offenders in several respects, a simple cross-tabular comparison of differential arrest likelihoods for white and nonwhite offenders may distort the actual influence of an offender's race on arrest likelihood. Therefore, a logistic regression analysis was performed to study the effect of offender race while controlling for other incident characteristics. (Logistic regression analysis results are presented in table 2 and are discussed below. See "How the Data Were Analyzed," page 6, for an explanation of methodology and terminology, including how the arrest "odds ratios" in the table relate to the text discussion of arrest odds.)

Overriding the finding of the simple crosstabular analysis, the logistic regression analysis found no difference in the likelihood of arrest for white and nonwhite juvenile offenders (see table 2). However, as shown in table 2, several other incident characteristics substantially affected the

${ }^{4}$ However, injuries by nonwhite offenders were more likely to be serious than were those by white offenders (7.9 percent versus 4.0 percent). likelihood of arrest. For example, the odds of an offender being arrested in a multiple-victim incident were about 41 percent greater than the odds of arrest in a single-victim incident. If more than one offender was involved, arrest odds decreased 85 percent. If a victim was injured, arrest odds increased 53 percent. If the victim was a member of the offender's family, the odds of arrest increased 54 percent (compared with the odds if the victim was a stranger). The odds of arrest increased if the victim was an adult (29 percent), a male (5 percent), or white (24 percent). The odds of arrest for a male offender were about 6 percent greater than the odds for a female offender.

Logistic regression equations were developed separately for white and nonwhite juvenile offenders to determine whether incident characteristics affecting likelihood of arrest differed for these two groups (see table 2). The incident characteristics that significantly increased the odds of arrest for violent crimes were largely the same for white and nonwhite offenders, with one important difference: victim race was correlated with arrest probability for nonwhite juvenile offenders but not for white offenders. A nonwhite juvenile offender was more likely to be arrested if the victim was white than if the victim was nonwhite.

The possible correlation between offender race and arrest was further explored by developing separate logistic regression equations for each of the 11 NIBRS states that reported at least 1,000 juvenile violent crime offenders. In eight states, white and nonwhite offenders had an equal likelihood of arrest; in two states, nonwhite offenders were more likely to be arrested; and in one state, white offenders were more likely to be arrested.

Arrest bias was also explored by conducting separate logistic regression analyses for five crimes: aggravated assault, intimidation, robbery, simple assault, and violent sexual assault. The offender's race was not significantly correlated with the likelihood of arrest for intimidation or violent sexual assault. The offender's race was significantly correlated with the likelihood of arrest for the other three crimes (aggravated assault, robbery, and simple assault), but the effect was that white offenders were more likely to be arrested than nonwhite offenders. 
Table 2: Logistic Regression To Predict Arrest of Violent Juvenile Offenders

\begin{tabular}{|c|c|c|c|c|c|c|}
\hline \multirow[b]{2}{*}{$\begin{array}{l}\text { Dichotomized } \\
\text { Independent Variable }^{\dagger}\end{array}$} & \multicolumn{2}{|c|}{$\begin{array}{l}\text { All Offenders } \\
(n=102,905)\end{array}$} & \multicolumn{2}{|c|}{$\begin{array}{c}\text { White Offenders } \\
\quad(n=71,246)\end{array}$} & \multicolumn{2}{|c|}{$\begin{array}{c}\text { Nonwhite Offenders } \\
(n=31,659)\end{array}$} \\
\hline & $\begin{array}{c}\text { Percent } \\
\text { Arrested }{ }^{\ddagger}\end{array}$ & $\begin{array}{l}\text { Odds } \\
\text { Ratio }\end{array}$ & $\begin{array}{c}\text { Percent } \\
\text { Arrested }\end{array}$ & $\begin{array}{l}\text { Odds } \\
\text { Ratio }\end{array}$ & $\begin{array}{c}\text { Percent } \\
\text { Arrested }\end{array}$ & $\begin{array}{l}\text { Odds } \\
\text { Ratio }\end{array}$ \\
\hline Number of victims & & \multirow[t]{3}{*}{$1.4076^{* *}$} & & \multirow[t]{3}{*}{$1.4049 * *$} & & \multirow[t]{3}{*}{$1.4019 * *$} \\
\hline One $(0)$ & 33.7 & & 35.5 & & 29.6 & \\
\hline More than one (1) & 36.3 & & 37.7 & & 33.5 & \\
\hline Number of offenders & & \multirow[t]{3}{*}{$0.5418^{* *}$} & & \multirow[t]{3}{*}{$0.5051 * *$} & & \multirow[t]{3}{*}{$0.6292 * *$} \\
\hline One $(0)$ & 38.9 & & 40.5 & & 34.5 & \\
\hline More than one (1) & 26.0 & & 26.3 & & 25.4 & \\
\hline Location of incident & & \multirow[t]{3}{*}{$1.1679 * *$} & & \multirow[t]{3}{*}{$1.1922^{* *}$} & & \multirow[t]{3}{*}{$1.1307 * *$} \\
\hline Outdoors (0) & 28.1 & & 29.7 & & 25.6 & \\
\hline Indoors (1) & 36.2 & & 37.5 & & 32.7 & \\
\hline Most serious weapon & & \multirow[t]{3}{*}{$1.2910^{* *}$} & & \multirow[t]{3}{*}{$1.3704^{* *}$} & & \multirow[t]{3}{*}{$1.1587 * *$} \\
\hline Personal (0) & 33.2 & & 34.7 & & 29.5 & \\
\hline Nonpersonal (1) & 38.5 & & 41.8 & & 33.4 & \\
\hline Victim age & & \multirow[t]{3}{*}{$1.2915^{* *}$} & & \multirow[t]{3}{*}{$1.2796^{* *}$} & & \multirow[t]{3}{*}{$1.3322^{* *}$} \\
\hline Juvenile (0) & 30.3 & & 31.9 & & 26.5 & \\
\hline Adult (1) & 40.1 & & 42.3 & & 35.6 & \\
\hline Victim sex & & \multirow[t]{3}{*}{$1.0505^{* *}$} & & \multirow[t]{3}{*}{$1.0513^{* *}$} & & \multirow[t]{3}{*}{$1.0380 \mathrm{~ns}$} \\
\hline Female (0) & 34.8 & & 36.4 & & 31.1 & \\
\hline Male (1) & 33.6 & & 35.3 & & 29.7 & \\
\hline Victim race & & \multirow[t]{3}{*}{$0.8036^{* *}$} & & \multirow[t]{3}{*}{$0.9577 \mathrm{~ns}$} & & \multirow[t]{3}{*}{$0.7359 *$} \\
\hline White $(0)$ & 35.5 & & 36.0 & & 32.6 & \\
\hline Nonwhite (1) & 29.5 & & 31.5 & & 29.2 & \\
\hline Was victim injured? & & \multirow[t]{3}{*}{$1.5322^{* *}$} & & $1.6545^{* *}$ & & $1.2788 * *$ \\
\hline No $(0)$ & 30.5 & & 31.3 & & 28.7 & \\
\hline Yes (1) & 38.4 & & 41.2 & & 32.3 & \\
\hline Was victim a family member? & & $1.5409 * *$ & & $1.4761 * *$ & & $1.7550 * *$ \\
\hline No $(0)$ & 30.6 & & 31.9 & & 27.8 & \\
\hline Yes (1) & 47.0 & & 48.4 & & 42.5 & \\
\hline Was victim an acquaintance? & & $0.9542^{*}$ & & $0.9213^{*}$ & & $1.0299 \mathrm{~ns}$ \\
\hline No $(0)$ & 41.5 & & 44.4 & & 35.3 & \\
\hline Yes (1) & 30.7 & & 31.9 & & 27.9 & \\
\hline Offender sex & & $1.0614^{* *}$ & & $1.0884^{* *}$ & & $0.9966 \mathrm{~ns}$ \\
\hline Female $(0)$ & 33.3 & & 34.8 & & 30.2 & \\
\hline Male (1) & 34.5 & & 36.2 & & 30.4 & \\
\hline Offender race & & $0.9617 \mathrm{~ns}$ & & & & \\
\hline White (0) & 35.9 & & & & & \\
\hline Nonwhite (1) & 30.4 & & & & & \\
\hline For explanation of terminology, $\mathrm{s}$ & ow the Data & lere Analyz & & & & \\
\hline $\begin{array}{l}\text { The assigned value code is given in } p \\
\text { "Percent arrested" is a simple percent } \\
\text { lue 0" and "value 1" conditions. } \\
p \leq .05 . \\
p \leq .001 . \\
=\text { not significant. }\end{array}$ & $\begin{array}{l}\text { ntheses. } \\
\text { of the samp }\end{array}$ & with no att & ontrol for the & riations of $\mathrm{i}$ & aracteristics & \\
\hline
\end{tabular}




\section{How the Data Were Analyzed}

Once the final sample of incident-based juvenile offender records was identified, statistical relations among various incident characteristics (independent variables) and arrest (dependent variable) were analyzed. The characteristics analyzed included number of victims and offenders, victim demographics, offender demographics (as perceived by the victims), location, weapon, injury, and victim-offender relationship. (If an incident involved more than one victim, the analysis used the characteristics of the first-listed victim.) For purposes of the analysis, the variables were dichotomized (i.e., expressed as a choice between two possibilities, with value codes of either 0 or 1 assigned to each possibility), as follows:

- Number of victims: $0=$ One; $1=$ More than one.

- Number of offenders: 0 = One; 1 = More than one.

Location of incident: 0 = Outdoors (e.g., roads and streets); 1 = Indoors (e.g., residences and schools).

- Most serious weapon: 0 = Personal (hands, feet); 1 = Nonpersonal (firearms, knives, clubs, etc.).

- Victim age: 0 = Juvenile; 1 = Adult.

- Victim sex: 0 = Female; 1 = Male.

Victim race: $0=$ White; $1=$ Nonwhite.

Victim injured? $0=$ No; 1 = Yes.

- Victim a member of offender's family? $0=$ No; $1=$ Yes.

- Victim an acquaintance of offender? $0=$ No; $1=$ Yes.

- Victim a stranger to offender? $0=\mathrm{No} ; 1=$ Yes.

- Offender sex: 0 = Female; 1 = Male.

- Offender race: 0 = White; $1=$ Nonwhite.

Offender arrested? $0=$ No; 1 = Yes.

The technique used to analyze these data-logistic regression-makes it possible to determine how each of the incident characteristics affects the probability that a juvenile offender will be arrested. Logistic regression compares the odds of an event occurring under one set of conditions with the odds of it occurring under an almost identical set of conditions. Odds represent a comparison of the probability of the event occurring to the probability of it not occurring. For example, in this study, 34.2 percent of all juvenile offenders reported by victims were arrested and 65.8 percent were not. Therefore, the odds of being arrested are 0.5198 (34.2 percent/65.8 percent). Stated in the reverse, the odds of not being arrested are 1.9240 (65.8 percent/34.2 percent). The simplest verbal summary is to say the juvenile offenders have odds of about 2 to 1 of not being arrested. If analysis finds that the odds of an event occurring in two slightly different situations are statistically different, then the difference between the two situations can be said to significantly affect the odds of the event occurring. For mathematical reasons, it is impossible to determine the true odds of arrest in two slightly different situations. However, logistic regression can test whether the average of the fraction formed by the ratio of the two odds (i.e., the odds ratio) across all situations is significantly different from 1. Mathematically, an odds ratio is always positive and can either be greater than 1 or less than 1, depending on which condition is considered to be in the numerator of the ratio.

Two examples may help to clarify how to interpret the findings of a logistic regression. In this study, the odds ratio of arrest in multiple-victim compared with single-victim violent crimes is 1.4076 . This ratio is statistically greater than 1 and can be read to imply that the odds of arrest in multiplevictim crimes average 40.76 percent greater than the odds of arrest in single-victim crimes. (Note that this is not a 40.76-percent greater probability of arrest but a 40.76percent greater odds of arrest.) Another finding from this study is a significant odds ratio of 0.5418 when comparing arrest odds for multiple-offender incidents with arrest odds for single-offender incidents. If this odds ratio were calculated comparing single-offender incidents with multipleoffender incidents, it would be 1.8457 (i.e., the reciprocal of 0.5418 , or $1 /[0.5418]=1.8457$ ). To simplify interpretation, therefore, this odds ratio of 0.5418 is thought of as a ratio of 1.8457 and is said to indicate that being a lone offender increases the odds of arrest an average of 84.57 percent across all possible incident situations.

\section{Summary and Discussion}

Overall, the NIBRS data offer no evidence to support the hypothesis that police are more likely to arrest nonwhite juvenile offenders than white juvenile offenders, once other incident attributes are taken into consideration. This holds true when the data are analyzed in the aggregate (i.e., for all states and crimes combined), at the state level, and within each crime category. In fact, there is some evidence to support the conclusion that once a violent crime is reported to or witnessed by police, the likelihood of arrest is greater for white juvenile offenders than for nonwhite juvenile offenders. The data do indicate, however, an indirect bias effect in the arrest of nonwhite juveniles in that they are more likely to be arrested when the victim is white than when the victim is nonwhite.

At one level, then, these data clearly show that police decisions to arrest youth for violent crimes are not affected by the youth's race. In the 17 states examined, no significant differences were found with regard to arrest decisions for white and nonwhite youth. Overall, crimes against white victims were more likely to result in arrest than were crimes against nonwhite victims.

A limitation of this study is that it summarizes the general arrest patterns of law enforcement agencies in 17 states that reported NIBRS data to the FBI in 1997 and 1998. Obviously, one cannot make generalizations beyond the data. Overall patterns might differ if other states were included in the sample. Additionally, different patterns might be found if analyses focused on individual communities within the sample. 
The possibility of racial bias in juvenile arrests is an important issue. The analyses reported in this Bulletin, regardless of their limitations, reveal no direct evidence that such bias exists in police arrests of juveniles for serious (and some nonserious) violent crimes.

\section{References}

Austin, J., Dimas, J., and Steinhardt, D. 1991. The Overrepresentation of Minority Youth in California's Secure Facilities. Prepared for the California Advisory Group on Juvenile Justice and the California Office of Criminal Justice Planning. San Francisco, CA: National Council on Crime and Delinquency.

Bridges, G., Conley, D., Biretta, G., and Eigen, R. 1993. Racial Disproportionality in the Juvenile Justice System. Report to the Department of Social and Health Service, State of Washington, Olympia, WA.

Bynum, T.C., Wordes, M., and Corley, J.C. 1993. Disproportionate Representation in Juvenile Justice in Michigan: Examining the Influence of Race and Gender. Technical Report prepared for the Michigan Committee on Juvenile Justice, East Lansing, MI.

Conley, D.J. 1994. Adding color to a black and white picture: Using qualitative data to explain disproportionality in the juvenile justice system. Journal of Research in Crime and Delinquency 31(2):135-148.

Hartstone, E., and Richetelli, D. 1995. An Assessment of Minority Overrepresentation in Connecticut's Juvenile Justice System. Hartford, CT: Spectrum Associates.

Lovell, R., and Pope, C.E. 1991. Discrimination or no discrimination: A methodological critique of the evidence. Critical Criminologist 3(2):1-2, $11,14$.

McCord, J., ed. 1997. Violence and Childhood in the Inner City. New York, NY: Cambridge University Press.

Pope, C.E. 1994. Racial disparities in the juvenile justice system. Overcrowded Times: Solving the Prison Problem 5(6):1, 5-7.

Pope, C.E. 1999. Crime and violence, popular misconceptions of. In Violence in America: An Encyclopedia, edited by R. Gottesman. New York, NY: Charles Scribner's Sons.

Pope, C.E., Lovell, R., Stojkovic, S., and Rose, H. 1996. Minority Overrepresentation: Phase II Study Final Report. Milwaukee, WI: Wisconsin Office of Justice Assistance, Governor's Commission on Juvenile Justice.

Sealock, M.D., and Simpson, S.S. 1998. Unraveling bias in arrest decisions: The role of juvenile offender type-scripts. Justice Quarterly 15(3):427-457.
Snyder, H.N. 1998. Juvenile Arrests 1997. Bulletin. Washington, DC: U.S. Department of Justice, Office of Justice Programs, Office of Juvenile Justice and Delinquency Prevention.

Snyder, H.N., and Sickmund, M. 1999. Juvenile Offenders and Victims: 1999 National Report. Washington, DC: U.S. Department of Justice, Office of Justice Programs, Office of Juvenile Justice and Delinquency Prevention.

Wilbanks, W. 1987. The Myth of a Racist Criminal Justice System. Pacific Grove, CA: Brooks/ Cole Publishing Company.

Wordes, M., Bynum, T.C., and Corley, C.J. 1994. Locking up youth: The impact of race on detention decisions. Journal of Research in Crime and Delinquency 31(2):149-165.

\section{Acknowledgments}

This Bulletin was written by Carl E. Pope, Ph.D., Professor in the Criminal Justice Program at the University of Wisconsin-Milwaukee, and Howard N. Snyder, Ph.D., Director of Systems Research at the National Center for Juvenile Justice. Some information contained in this Bulletin was originally presented at the annual meeting of the American Society of Criminology, San Francisco, CA, November 2000.
This Bulletin was prepared under grant number 99-JN-FX-K002 from the Office of Juvenile Justice and Delinquency Prevention, U.S. Department of Justice. This grant was provided to the National Center for Juvenile Justice in support of its National Juvenile Justice Data Analysis Project.

The Office of Juvenile Justice and Delinquency Prevention is a component of the Office of Justice Programs, which also includes the Bureau of Justice Assistance, the Bureau of Justice Statistics, the National Institute of Justice, and the Office for Victims of Crime.

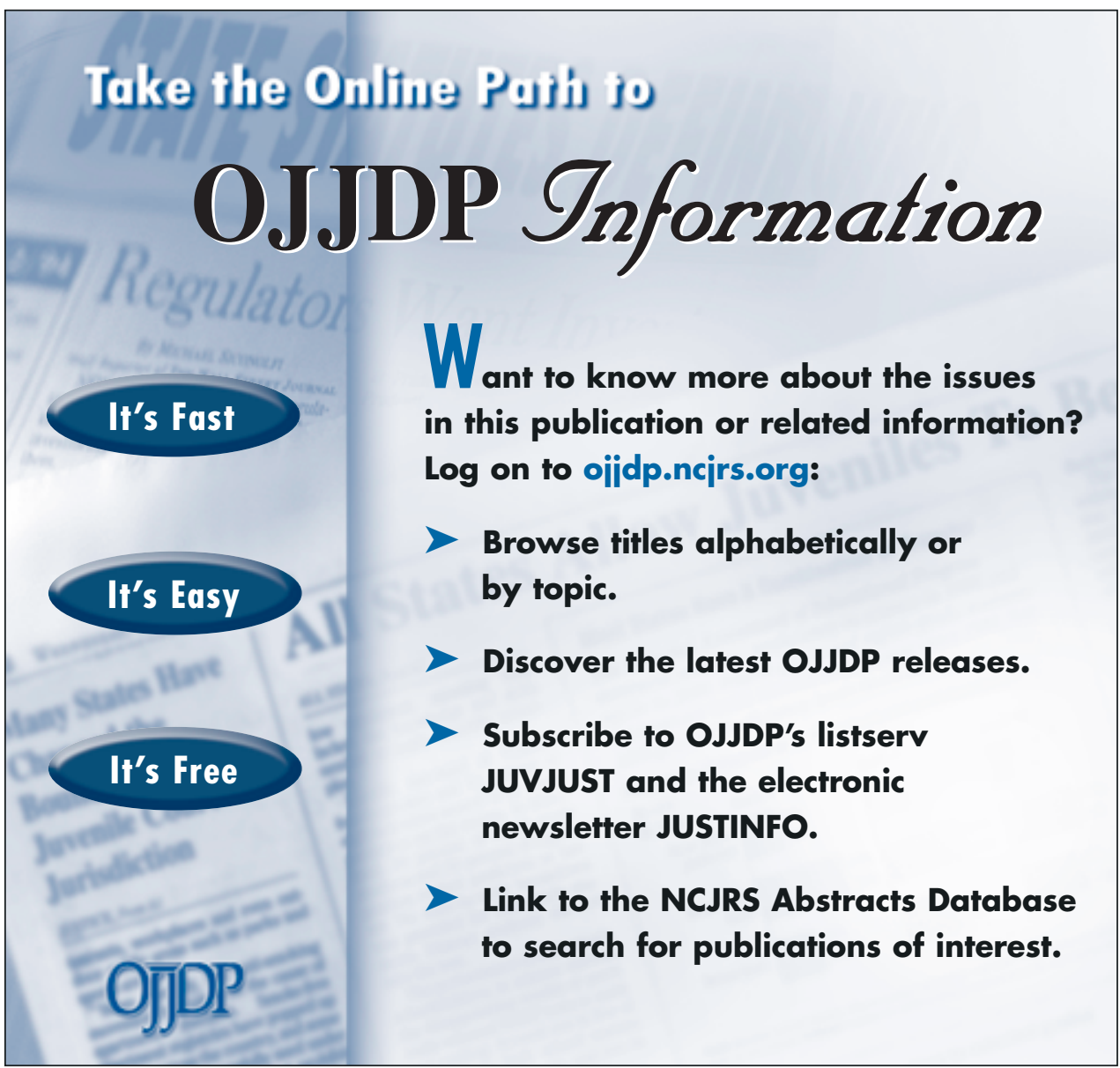




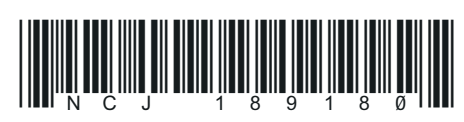

